their colours firmly to the mast in the first paragraph. It is a relief, therefore, to find that they achieve their aim without a hint of over-reaction and have produced an eminently readable and balanced account of wound care.

The first chapter is an excellent overview of wound care where the biology of wound healing is linked from the outset to established clinical principles. The authors consider a range of treatment options from primary closure to free grafting and even include some helpful advice on the choice of dressings. They introduce the concept of 'wound control', a theme which unites the book, and include some useful advice on the management of patients with systemic inhibition of healing.

The second chapter considers the 'common pathway' of wound healing which is kept lively by the use of clinical examples.

The rest of the book is, first, an overview of common wounds which then gradually polarizes to specific situations such as burns and bites, and, then, an interesting concluding chapter on difficult wounds. Specific clinical examples are given throughout which serve to re-emphasize the principles already outlined.

This book is an excellent, coherent account of wound care which states an aim and then proceeds to achieve it. As such, it deserves to be read in sequence rather than dipped into. This is an easy task as it is well written, uncluttered and relatively short. It is full of practical advice which is detailed enough to be useful without being so specific as to be constrictive. I am happy to recommend this book to anyone involved in wound care.

ANTHONY P. WETHERALL

Registrar in Accident and Emergency Medicine, Hope Hospital, Salford, England

\title{
Radiology in Emergency Medicine
}

By R. C. Levy, H. H. Hawkins JR \& W. G. BarsaN

Blackwell Scientific Publications, Oxford. 1986. 450pp. £59.00.

This book is jointly written by two clinicians and a radiologist from Cincinnati. It attempts the almost impossible task of reviewing all the radiology seen on patients presenting in the emergency department. A very good feature is that newer imaging modalities such as C. T. and ultrasound are included as emergency procedures. Even in Great Britain, where C. T. availability is patchy, it is an important method of investigation and, especially in seriously ill patients, may provide much information, which cannot be obtained by plain film radiography.

The preface states that it does not include large numbers of normal variants and, whilst there is already good literature on this subject, this does cause confusion to the casualty officer. Similarly, much emergency work involves children and a quick series of pictures of bones and skull at different ages would be very helpful to the junior casualty officer. 
The subject is divided into anatomical regions and each region is divided into traumg and non-trauma, which is helpful. Naturally, not all topics can be covered in one book and sometimes the choice of topics is a little bizarre. Nobody can attempt ches radiology in 40 pages and the authors state this in the preface.

As a Radiologist, I find it a book for and by clinicians and it has very much the feel of picture matching - but we all do this in difficult situations.

The classical trauma sections will appeal to the radiologists more than the chest and abdominal sections.

The casualty officer will find the tables of imaging techniques useful but it would have्छ been helpful if some guidance had been given about the feasibility of different views or 5 ill patients. Much trauma is initially investigated in the on-call situation when both medical or radiographic staff are relatively junior.

All in all, this book attempts an impossibly large subject and can't cover it adequatelys all the time. Nevertheless, it will have a place on the desk in the casualty department. and, by radiological book standards, it is quite cheap.

\section{J. A. HAYWORTH}

Consultant Radiologist, University Hospital of South Manchester, Manchester, England

\section{Médecine de Catastrophe}

By Dr René Noto, Pierre Huguenard \& Alain larcan Masson, Paris. 1987. 600pp. 165F.

This book is a volume in the publisher's series of 'Notes on Medicine'. It is written by the Chief Medical Officer of the Paris fire brigade (Dr R. Noto) and by the directors of $B$ two well-known units in the SAMU (Service d'aide médicale urgente) system. The book is probably aimed at those studying for a forthcoming diploma in disaster. medicine.

For anyone concerned with this subject this is an interesting book with its allembracing approach to the medical and other aspects of disasters. This is necessary? when one considers the wide range of these events, even in Europe (for example, floods, forest fires, earthquakes and volcanic eruptions).

To English eyes this is a very 'French' book. For instance, the first 40 pages deal with? the definition of a catastrophe. This is necessary for the French disaster plan which lays. down the legal roles of everyone from the local mayor to minister. In addition to then main overall plan, there are 14 sub plans to deal with specific types of disaster, again covered by various ministerial decrees.

The authors deal fully with the disposition of the forces, medical, paramedical and other (e.g. army), needed along with the equipment required, including aircraff (helicopter and fixed-wing). They discuss methods of triage and evacuation of casualties and the disposal of dead. Nearly 300 pages are concerned with diagnostic techniques, ? 